\title{
MORPHOMETRIC AND ELECTRON MICROSCOPIC CHANGES OF STRUCTURAL COMPONENTS OF LYMPH NODES DURING CORRECTION OF THE ACTION OF SODIUM GLUTAMATE WITH ORLISTAT
}

D0I: 10.36740/WLek202109106

\author{
Tetiana V. Harapko', Lesia R. Mateshuk-Vatseba ${ }^{2}$ \\ 1 UZHHOROD NATIONAL UNIVERSITY, UZHHOROD, UKRAINE \\ ${ }^{2}$ LVIV NATIONAL MEDICAL UNIVERSITY NAMED AFTER DANYLO HALYTSKYI, LVIV, UKRAINE
}

\begin{abstract}
The aim: To study morphometric and electron microscopic changes in the parenchyma of rat lymph nodes under the action of sodium glutamate and its correction by orlistat. Materials and methods: The article presents and analyzes the data of an experimental study conducted on 66 white male rats and females of reproductive age. Experimental animals are divided into 4 groups.

Results: After six weeks of exposure to monosodium glutamate, there was a significant decrease in the relative area of the cortical substance in the lymph nodes of white male and female rats by $11.95 \%$ and $9.31 \%$ and, respectively, an increase in the relative area of the medullary substance by $18.76 \%$ and $14.7 \%$ in compared with an intact group of animals. After six weeks of sodium glutamate and the next six weeks of the standard diet of vivarium and orlistat, the relative area of the cortical substance in the lymph node parenchyma was $2.55 \%$ and $0.38 \%$ more than the parameters of the intact group of animals, respectively. Accordingly, the relative area of the medullary substance decreased and was $4.01 \%$ and $0.59 \%$ less compared to the intact group of animals.
\end{abstract}

Conclusions: Electron microscopic examination showed that monosodium glutamate causes changes in the parenchyma of the lymph nodes as in a high-calorie diet. The introduction of orlistat (xenical) leads to a partial restoration of the structural organization, and hence the function of this organ.

KEY WORDS: sodium glutamate, orlistat, correction, lymphocyte, endotheliocyte

Wiad Lek. 2021;74(9 p.l):2060-2065

\section{INTRODUCTION}

It is difficult now to imagine the food industry without the use of food additives. The latter include sodium glutamate, which not only enhances the taste of foods, but increases appetite, which in turn leads to an increase in the amount of food consumed, which contains food additives, closing the circle, which is the basis of high-calorie diet (HCD) used in the study $[1,2]$. An urgent issue today, both medical and social, is to study the effects of supplements, including monosodium glutamate, on the state of the body as a whole and tissues and organs directly, because it is one of the most common food supplements in the world [3-5].

The literature describes some studies performed on animals using this additive. Sodium glutamate has been shown to be detrimental to the testes of Wistar rats, as many cells of spermatogenesis of various types have been found to be necrotic with pyknotic nuclei, and the vessels have dilated and overflowed. Prolonged use of monosodium glutamate can cause male infertility [6]. Causes an increase in serum estrogen and progesterone levels in adult female rats [7]. The results show that monosodium glutamate increases lipid peroxidation, nitric oxide, neurotransmitters, and is accompanied by the accumulation of $ß$-amyloid peptides in the body compared to normal control rats [8]. Studies have been described in which sodium glutamate at a dose of $0.04 \mathrm{mg} / \mathrm{kg}$ and $0.08 \mathrm{mg} / \mathrm{kg}$ was mixed with flour and fed to adult female rats daily. As a result, pathological changes in the ovaries [9] and fallopian tubes [10] were detected. Studies have concluded that monosodium glutamate has a neurotoxic effect, leading to degenerative changes in neurons and astrocytes in the cerebellar cortex of albino rats [11]. Animal studies show that monosodium glutamate leads to obesity [12].

However, there are insufficient data in the literature on the effects of monosodium glutamate on lymphoid organs. Of particular interest are the organs of the immune system, as they protect the body from foreign cells and substances, providing homeostasis of the body, including lymph nodes, which are also called biological «filters». Also no less important is the correction of changes caused by the action of monosodium glutamate on the body. Our chosen orlistat (xenical) is a drug with a peripheral mechanism of action, it is a powerful and specific inhibitor of gastrointestinal lipases, has a long-lasting effect $[13,14]$. 


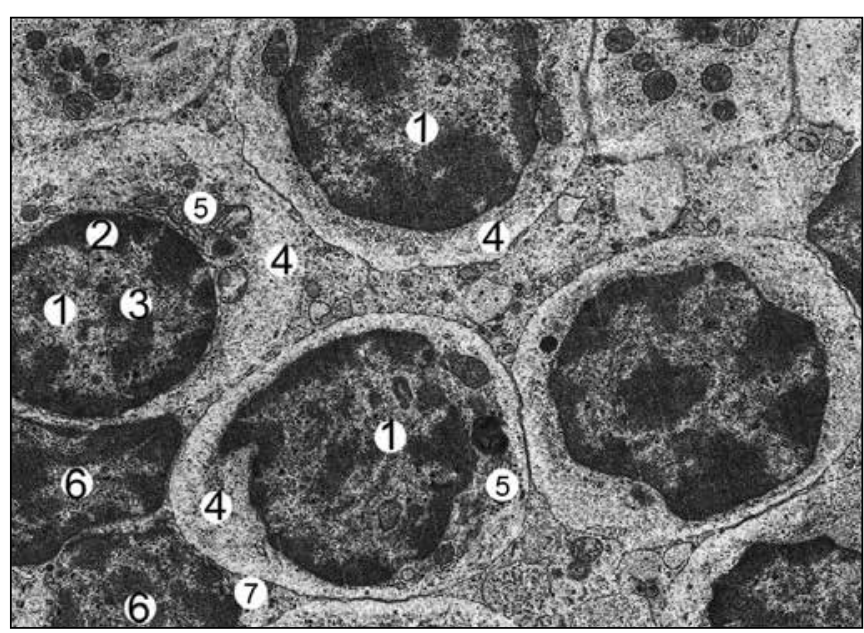

Fig. 1. Electron microscopic organization of the cortical substance of the mesenteric lymph node of the white rat female of the intact group. Electronic micrograph. Approx. $\times 6000$. Designation: euchromatin (1), heterochromatin (2) and nucleolus (3) in the nucleus of the middle lymphocyte; the cytoplasm (4) contains ribosomes (5); nucleus (6) and cytoplasm (7) of a small lymphocyte.

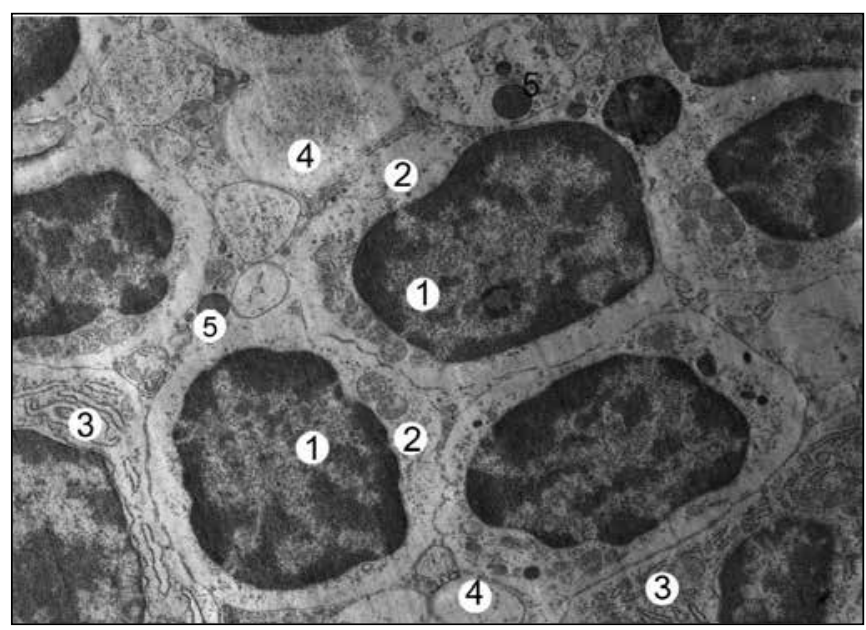

Fig. 3. Electron microscopic organization of the cortical substance of the mesenteric lymph node of a white male rat after six weeks of $H C D$, followed by two weeks of orlistat. Electronic micrograph. Approx. $\times 6000$. Designation: 1 - nucleus of an average lymphocyte with an uneven contour of a karyolema; 2 - enlightened cytoplasm; 3 - swollen and dilated granular endoplasmic reticulum; 4 - vacuole-like structures in the intercellular space; 5 - osmophilic (fatty) inclusions.

\section{THE AIM}

The aim of the study to study the morphometric and electron microscopic changes in the structural components of the lymph nodes of rats in the correction of the action of monosodium glutamate with orlistat.

\section{MATERIALS AND METHODS}

The study was performed on 66 white male rats and females of reproductive age (2.5-6.5 months) weighing 120-260 g.

The microanatomy of the structural components of the mesenteric lymph nodes of white rats under physiological norms was studied on 10 intact animals. Experimental

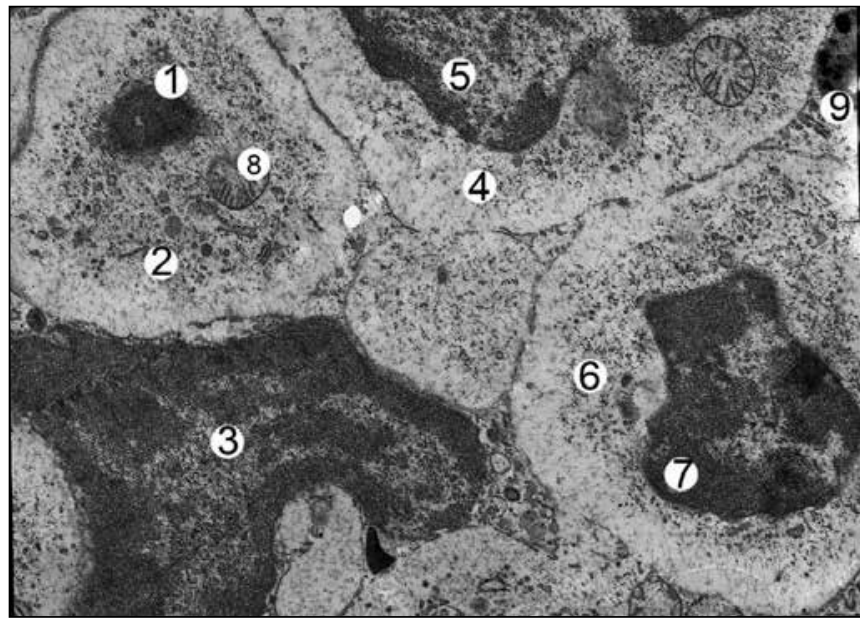

Fig. 2. Electron microscopic organization of the lymphoid nodule of the mesenteric lymph node of a white female rat after six weeks of HCD. Electronic micrograph. Approx. $\times 6000$. Designation: 1-karyolysis of lymphocytes; 2 - cytoplasm; 3 - deformed reticulo-endothelial cells nucleus; the nucleus (4) and cytoplasm (5) of the lymphoblast; the nucleus (6) and cytoplasm (7) of the middle B-lymphocyte; 8 - ribosome with signs of edema and destruction; 9 - osmophilic (fatty) inclusions.

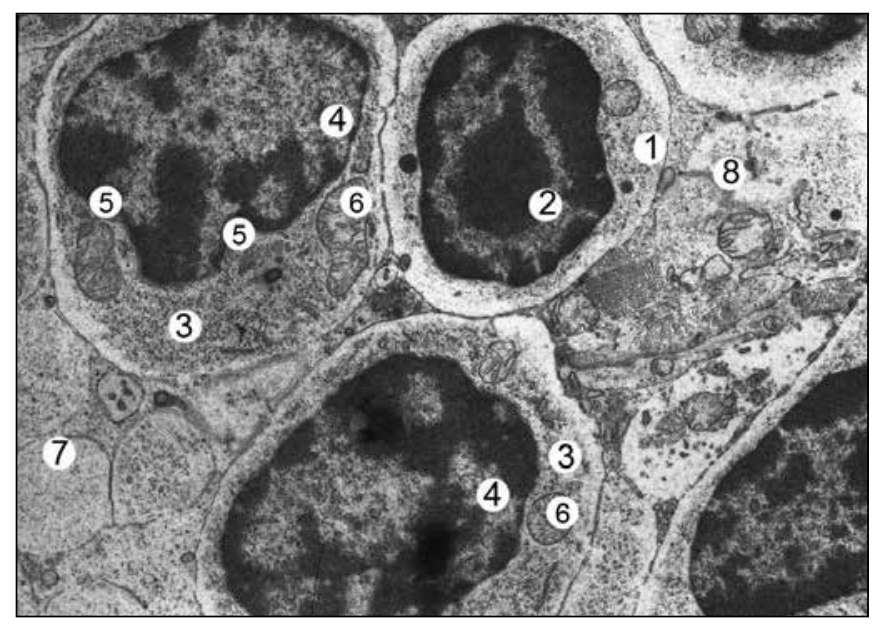

Fig. 4. Electron microscopic organization of the cortical substance of the mesenteric lymph node of a white female rat after six weeks of HCD, followed by four weeks of orlistat. Electronic micrograph. Approx. $\times 8000$. Designation: cytoplasm (1) and nucleus (2) of a small lymphocyte; cytoplasm (3) and nucleus (4) of the middle lymphocyte; 5 - uneven contours of the cariolema; 6-ribosome with signs of edema and destruction; 7-vacuole-like structures in the intercellular space; 8 - area of destructive changes.

animals were divided into 4 groups: the first group (10 animals), which were fed HCD for six weeks; the second group (10 animals), which were fed HCD for six weeks, then transferred to the standard diet of vivarium and xenical was administered for two weeks; the third group (10 animals) and the fourth group (10 animals) were the same as the previous one, but xenical was used for four and six weeks, respectively. There were 5 male rats and 5 female rats in each group. HCD was achieved by adding to the diet of monosodium glutamate at a dose of $0.07 \mathrm{~g} / \mathrm{kg}$ 


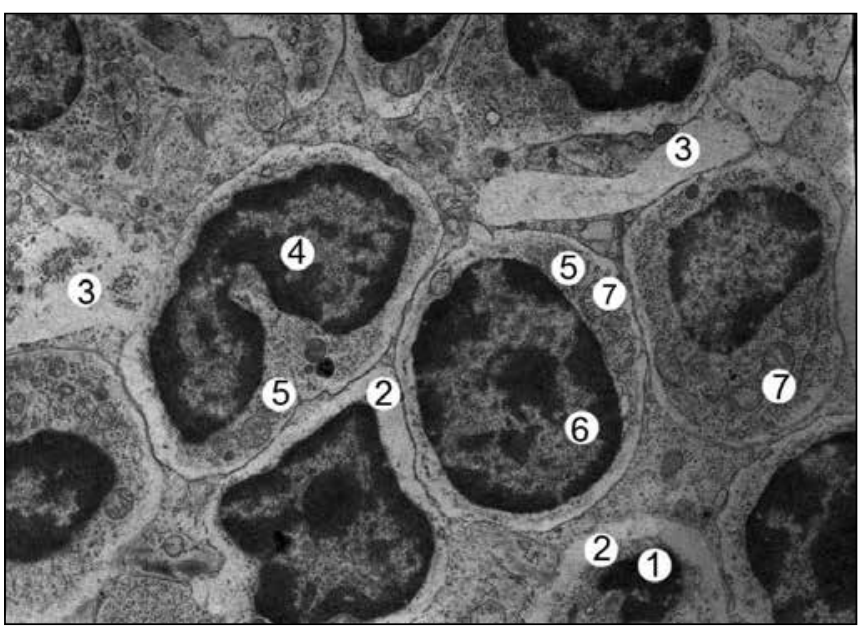

Fig. 5. Electron microscopic organization of the mantle zone of the lymphoid nodule of the mesenteric lymph node of a white female rat after six weeks of VKD, followed by six weeks of orlistat. Electronic micrograph. Approx. $\times 6000$. Designation: 1 - karyolysis of lymphocytes; 2 - destructured cytoplasm; 3 - expanded intercellular space; deformed nucleus (4) and cytoplasm (5) of lymphocytes; 6 - the nucleus of the middle B-lymphocyte; 7 - ribosome with signs of edema and destruction.

body weight of rats. The dose of xenical was $4.5 \mathrm{mg} /$ $\mathrm{kg}$ body weight of rats, administered orally daily at the same time.

The control was 16 white rats, which instead of a high-calorie diet received a standard diet of vivarium.

All experimental animals were kept in the vivarium of Lviv National Medical University named after Danylo Halytskyi. The research was conducted in accordance with the provisions of the «European Convention for the Protection of Vertebrate Animals Used for Experimen- tal and Other Scientific Purposes» (Strasbourg, 1986), Council of Europe Directives 86/609 / EEC (1986), Law of Ukraine №3447 - IV «On protection of animals from cruel treatment», general ethical principles of animal experiments, approved by the First National Congress of Ukraine on Bioethics (2001).

Before the material was taken, the animals were numbed with anesthesia. Fixation of pieces of lymph nodes was performed with a $1.5 \%$ solution of osmium trioxide in 0.2 $\mathrm{M}$ sodium cacodylate solution at $\mathrm{pH} 7.2$ for $2-2.5$ hours in the cold. Dehydration in increasing concentrations of ethyl alcohol $\left(50^{\circ}, 70^{\circ}, 90^{\circ}\right.$ and absolute) for 30 minutes each and propylene oxide for 10 minutes. The material was poured into a mixture of epoxy resins and polymerized for 24 hours in a thermostat at $60^{\circ} \mathrm{C}$. Sections were made on an ultramicrotome UMTP-6M with a diamond knife (DIATOM) and double contrast was performed according to Reynolds and uranyl acetate. Submicroscopic examinations of the organ were performed using an electron transmission microscope TEM-100. The investigated material was photodocumented using a SONY H9 digital camera.

Morphometric studies were performed on time on histological specimens stained with hematoxylin and eosin using VideoTest-5.0, KAARA Image Base, Stepanizer and Microsoft Excel on a personal computer. Statistical processing of digital data was performed using software "Excel" and "STATISTICA" 6.0 using the parametric method. The numerical values of the parameters are represented by sample mean values $(M)$, standard deviation $(\sigma)$, standard error of the mean value $(\mathrm{m})$, Student's criterion $(\mathrm{t})$. The results of the calculations were presented in graphical form in the form of histograms using Microsoft Office, indicating confidence intervals at a confidence level of $95 \%(p=0.95)$.

Table I. Dynamics of changes in the relative area of cortical and medullary substances and cortical-medullar index (CMI) of lymph nodes of white male rats of intact and experimental groups $(\mathrm{M} \pm \mathrm{m})$

\begin{tabular}{|c|c|c|c|}
\hline Group name & S $_{\text {cortic.subst. }}, \%$ & $\mathbf{S}_{\text {medul.subst. }}, \%$ & CMI \\
\hline Intact animals & $61.08 \pm 1.56$ & $38.92 \pm 0.78$ & $1.57 \pm 0.11$ \\
\hline I group - 6 weeks HCD & $53.78 \pm 1.38 *$ & $46.22 \pm 0.7 *$ & $1.16 \pm 0.13 *$ \\
\hline II group - 6 weeks HCD, 2 weeks xenical & $57.96 \pm 1.31 *$ & $42.04 \pm 0.65 *$ & $1.38 \pm 0.09$ \\
\hline III group - 6 weeks HCD, 4 weeks xenical & $67.04 \pm 1.23 *$ & $32.96 \pm 0.61 *$ & $2.03 \pm 0.11 *$ \\
\hline IV group - 6 weeks HCD, 6 weeks xenical & $62.64 \pm 1.28$ & $37.36 \pm 0.7$ & $1.68 \pm 0.1$ \\
\hline
\end{tabular}

Notes: ${ }^{*}$ - values that are statistically significantly different from those of the intact animal group $(p<0.05)$

Table II. Dynamics of changes in the relative area of cortical and medullary substances and cortical-medullar index (CMI) of lymph nodes of white female rats of intact and experimental groups $(\mathrm{M} \pm \mathrm{m})$

\begin{tabular}{|c|c|c|c|}
\hline Group name & $\mathbf{S}_{\text {cortic.subst. }} \%$ & $\mathbf{S}_{\text {medul.subst. }} \%$ & CMI \\
\hline Intact animals & $61.23 \pm 1.7$ & $38.77 \pm 0.76$ & $1.58 \pm 0.11$ \\
\hline I group - 6 weeks HCD & $55.53 \pm 1.29 *$ & $44.47 \pm 0.71 *$ & $1.25 \pm 0.2 *$ \\
\hline II group - 6 weeks HCD, 2 weeks xenical & $57.37 \pm 1.42 *$ & $42.63 \pm 0.68 *$ & $1.35 \pm 0.18$ \\
\hline III group - 6 weeks HCD, 4 weeks xenical & $67.85 \pm 1.38 *$ & $32.15 \pm 0.74 *$ & $2.11 \pm 0.1 *$ \\
\hline IV group - 6 weeks HCD, 6 weeks xenical & $61.46 \pm 1.41$ & $38.54 \pm 0.65$ & $1.59 \pm 0.12$ \\
\hline
\end{tabular}

Notes: * - values that are statistically significantly different from those of the intact animal group $(p<0.05)$ 


\section{RESULTS}

According to our histological and electron microscopic studies, the structure of the mesenteric lymph nodes of male and female rats of reproductive age of the intact and control groups is typical, corresponds to the species norm. The connective tissue capsule surrounds the parenchyma of the lymph node, giving numerous cortical and medullary trabeculae in the thickness of the organ. The parenchyma consists of a darker area of the cortical substance, which is located in the peripheral area, and lighter the medullary substance, which is closer to the hilum of the node.

Submicroscopically small, middle and large lymphocytes have a typical structure. The diameter of small lymphocytes is about 6-7 $\mu \mathrm{m}$, the nucleus occupies the predominant part of the lymphocyte, the cytoplasm surrounds it with a thin area. The diameter of the middle lymphocytes is about 7-9 $\mu \mathrm{m}$, their nucleus is more round, the nucleolus is clearly expressed, the cytoplasm contains ribosomes, granular endoplasmic reticulum and mitochondria (Fig. 1 ). The diameter of large lymphocytes (lymphoblasts) is about $10 \mu \mathrm{m}$, the main part of the nucleus is occupied by euchromatin, the contour of the nuclear membrane is smooth. The cytoplasm of lymphoblasts contains mitochondria and ribosomes. In macrophages, the nucleus has a different shape, the cytoplasm contains primary and secondary phagosomes.

After six weeks of HCD, a decrease in the relative area of the cortical substance in the parenchyma of the lymph nodes of white male and female rats by $10.2 \%$ and $5.3 \%$, respectively, compared with the previous group of animals, and is $12.0 \%$ and $9.3 \%$ less indicators of the intact group of animals (Tables. I, II). Respectively, the relative area of medullary substance increases by $15.2 \%$ and $7.5 \%$ compared to the previous group of animals, and is $18.8 \%$ and $14.7 \%$ more parameters of the intact group of animals (Tables I, II). CMI decreases in both male and female rats by $22.1 \%$ and $12.0 \%$, respectively.

Submicroscopically, after six weeks of HCD, the number of lymphocytes with signs of nuclear damage increases, mostly they are in the stage of karyorrhexis or karyolysis (Fig. 2). Some lymphocytes in which there are no signs of apoptosis have deep intussusception of the nuclear membrane. The cytoplasm of lymphocytes is enlightened, organelles are damaged. Significantly increases the number of macrophages in the cytoplasm of which a large number of lysosomes containing fragments of damaged lymphocytes and other osmophilic (fat) inclusions. Reticular endothelial cells contain enlarged and deformed nuclei, their cytoplasm contains damaged organelles, namely mitochondria with an enlightened matrix, tubules of granular endoplasmic reticulum swollen, dilated.

The basement membrane of blood capillaries is swollen, thickened, the nuclei of endothelial cells are deformed, the lumenal surface of the plasma membrane contains numerous microvilli, which reduce the lumen of the vessel. The proportion of collagen fibers and microfibrils in the parenchyma of the node increases. The wall of arterioles is thickened, sclerosed, the nuclei of endothelial cells are large. There are through defects in the capillary wall, venous full blood.

After six weeks of HCD, followed by two weeks of orlistat, an increase in the relative area of the cortical substance in the parenchyma of the lymph nodes of white male and female rats by $7.78 \%$ and $3.31 \%$, respectively, compared with the previous group of animals, which is $5.11 \%$ and $6.30 \%$ less than intact animals (Tables I, II). Respectively, the relative area of the medullary substance decreases by $9.04 \%$ and $4.14 \%$ compared to the previous group of animals, and is $8.02 \%$ and $9.96 \%$ more than the parameters of the intact group of animals (Tables I, II). CMI decreases in both male and female rats by $18.97 \%$ and $8.0 \%$, respectively.

Electron microscopically in the second group of studied animals, all detected changes are similar to the previous group. In the parenchyma of the lymph nodes a large number of lymphocytes with signs of damage to the nucleus, the cytoplasm is enlightened, the organelles are damaged, the intercellular space is expanded. A large number of osmophilic (fatty) inclusions both in the intercellular space and in the cytoplasm of macrophages (Fig. 3). The lumen of the hemocapillaries is narrowed due to numerous protrusions and microvilli of the cytolema of endothelial cells, in cross section it has a star shape. Some areas of hemocapillaries are so narrow that they do not allow blood cells to pass.

After six weeks of HCD, followed by four weeks of xenical, an increase in the relative area of the cortical substance in the lymph node parenchyma of male and female white rats was found by $15.67 \%$ and $18.27 \%$, respectively, compared to the previous group of animals, which is $9.76 \%$ and $10.81 \%$ more than the intact group of animals (Tables I, II). Respectively, the relative area of the medullary substance decreases by $21.6 \%$ and $24.58 \%$ compared to the previous group of animals, and is $15.31 \%$ and $17.08 \%$ less than the parameters of the intact group of animals (Tables I, II). CMI decreases in both male and female rats by $47.1 \%$ and $56.3 \%$, respectively.

Electron microscopically in the second group of studied animals it was found that the proportion of destructive changes decreased slightly compared to previous experimental groups. The intercellular space is expanded, the share of collagen fibers and microfibrils in the parenchyma of the node is increased in comparison with the intact group of animals. As in the previous groups, the number of macrophages is increased, their cytoplasm contains fragments of damaged lymphocytes and osmophilic inclusions. The lumen of hemocapillaries is narrowed, the basement membrane is thickened, swollen. In the cytoplasm of lymphocytes, some organelles are damaged (Fig. 4).

After six weeks of HCD, followed by six weeks of orlistat, a decrease in the relative area of the cortical substance in the lymph node parenchyma of white male rats and females by $6.56 \%$ and $9.42 \%$, respectively, compared with the previous group of animals, which is $2.55 \%$ and $0.38 \%$ more parameters of the intact group of animals (Tables I, II). Respectively, the relative area of the medullary substance increases by $13.35 \%$ and $19.88 \%$ compared to the 
previous group of animals, and is $4.01 \%$ and $0.59 \%$ less than the parameters of the intact group of animals (Tables I, II). $\mathrm{CMI}$ in male and female rats is $7.01 \%$ and $1.27 \%$ higher than the intact group of animals, respectively.

Electron microscopically in the third group of studied animals among the unaltered lymphocytes there are destructively altered cells, the nuclei of which have signs of pyknosis, mitochondria contain damaged mitochondrial ridges (Fig. 5). Reticular endothelial cells contain enlarged nuclei and thickened processes.

\section{DISCUSSION}

Studies conducted by the authors indicate that chronic administration of monosodium glutamate causes oxidative stress and alters the metabolic processes of glucose in the renal tissues of rats. Oxidative stress induced by monosodium glutamate in the renal tissues of rats is a consequence of the increase in the concentration of glucose in the tissues as a result of renal gluconeogenesis after administration of this substance. The authors concluded that individuals with impaired glucose metabolism should be careful in consuming monosodium glutamate [15].

From the results of a study conducted on white albino male rats (Wistar rats) weighing about $100 \pm 20 \mathrm{~g}$, which were fed HCD, and the control group received HCD +2 $\mathrm{mg} / \mathrm{kg}$ per day of orlistat, the authors concluded that there is a significant the relationship between a high-calorie diet and structural changes in the kidneys, accompanied by increased levels of urea, creatinine, uric acid, low-density lipoprotein. In the renal parenchyma there was a decrease in the numerical density of the glomeruli, pronounced dilatation of the renal vessels, tubules, necrosis and atrophy of the glomeruli and thickening of the basement membrane. In the renal parenchyma of male rats from the group receiving orlistat, a decrease in the level of circulating lipids in the blood, a decrease in body weight of rats, a decrease in signs of destructive changes in the renal parenchyma [14].

A study was described in male rats fed a high-calorie diet to correct orlistat $12 \mathrm{mg} \mathrm{kg}$ and/or amphetamine 1.5 $\mathrm{mg} / \mathrm{kg}$ for six weeks. It is concluded that both orlistat and amphetamine correct changes caused by a high-fat diet that led to obesity in animals. Orlistat works by suppressing the level of pancreatic lipase, and amphetamine can reduce weight by suppressing appetite. The two drugs have potential lipid properties and limited antioxidant activity and a regulatory role in blood glucose and insulin levels. Treatment with orlistat alone is more potent than treatment with amphetamine or two drugs in combination to reduce weight and improve weight-related medical complications. Moreover, treatment with orlistat is safe, while amphetamine administration is associated with serious side effects, including liver damage [13].

Similar results were obtained in a study where obesity caused by a high-calorie diet leads to cell death and macrophage activation. The authors concluded that inflammation associated with obesity induces fibrosis in the lymph nodes and is likely to increase the lumen of the sinuses and subsequently reduce the interaction of immune cells. The resulting effects of immune regulation are likely to contribute to the suppression of immunosuppression and lymphatic vascular dysfunction during obesity [16].

Obesity caused by diet in mice leads to significant dysfunction of the lymphatic system, which is reflected in a decrease in lymph flow, changes in the architecture of the lymph nodes and impaired migration of dendritic cells. Using various methods, it was found that obesity leads to disruption of lymph transport in the subcutaneous tissue and its drainage to the site of lymph nodes [17].

Similar changes at the submicroscopic level were found in the lymph nodes during prolonged exposure to the opioid nalbuphine. The authors describe that six-week and eight-week administration of the opioid nalbuphine leads to pathological changes in the lymph nodes at the submicroscopic level: decreases the number of lymphoblasts with signs of mitosis, increases the number of lymphocytes with significant changes in nuclei and damaged organelles in the cytoplasm. the phenomena of preapoptosis and apoptosis; intercellular spaces increase [18].

The authors describe that under a high-calorie diet in the parenchyma of the lymph nodes increases the proportion of macrophages and stromal cells that contain lipid inclusions. In this study, the authors showed that stromal cells express a large number of genes involved in lipid metabolism, indicating that lymph nodes are involved in lipid metabolism [19].

\section{CONCLUSION}

As a result of a study conducted on male and female rats, we found:

1. After six weeks of HCD, the relative area of the cortical substance in the parenchyma of the lymph nodes of white male and female rats decreased significantly by $11.95 \%$ and $9.31 \%$, and the relative area of the medullary substance increased by $18.76 \%$ and $14.7 \%$, respectively. with an intact group of animals.

2. After six weeks of HCD, followed by six weeks of orlistat, the relative area of the cortical substance in the lymph node parenchyma of white male and female rats is only $2.55 \%$ and $0.38 \%$ more, respectively, the parameters of the intact group of animals. The relative area of the medullary substance is $4.01 \%$ and $0.59 \%$ less than the parameters of the intact group of animals.

3. Electron microscopic examination showed that monosodium glutamate causes changes in the parenchyma of the lymph nodes as in a high-calorie diet. The introduction of orlistat (xenical) leads to a partial restoration of the structural organization, and hence the function of this organ.

\section{REFERENCES}

1. Husarova V., Ostatnikova D. Monosodium glutamate toxic effects and their implications for human intake: a review. JMED Res. 2013:1-12. doi: $10.5171 / 2013.608765$. 
2. Moneim W.M.A., Yassa H.A., Makboul R.A., Mohamed N.A. Monosodium glutamate affects cognitive functions in male albino rats. Egypt J Forensic Sci. 2018;8(1):9. doi: 10.1186/s41935-018-0038-x.

3. Nnadozie J.0., Chijioke U.0., Okafor 0.C. et al. Chronic toxicity of low dose monosodium glutamate in albino Wistar rats. BMC Res Notes. 2019;12:593 doi:10.1186/s13104-019-4611-7.

4. Tawfik M.S., Al-Badr N. Adverse effects of monosodium glutamate on liver and kidney functions in adult rats and potential protective effect of vitamins C and E. Food and Nutrition Sciences. 2012;3:651-659. doi:10.4236/fns.2012.35089.

5. Zanfirescu A., Cristea A.N., Nitulescu G.M. et al. Chronic Monosodium Glutamate Administration Induced Hyperalgesia in Mice. Nutrients. 2017; 10(1):1. doi: 10.3390/nu10010001.

6. Alalwani A.D. Monosodium glutamate induced testicular lesions in rats (histological study). Middle East Fertil Soc J. 2014;19:274-280. doi:10.1016/j.mefs.2013.09.003.

7. Zia M.S., Qamar K., Hanif R., Khalil M. Effect of monosodium glutamate on the serum estrogen and progesterone levels in female rat and prevention of this effect with diltiazem. J. Ayub. Med. Coll. Abbottabad. 2014;26(1):18-20.

8. Hussein U.K., Hassan N.E-H.Y., Elhalwagy M.E.A. et al. Ginger and Propolis Exert Neuroprotective Effects against Monosodium Glutamate-Induced Neurotoxicity in Rats. Molecules. 2017;22(11):1928. doi:10.3390/ molecules22111928.

9. Eweka A.0., Om'iniabohs F.A.E. Histological Studies of the Effects of Monosodium Glutamate on the Ovaries of Adult Wistar Rats. Annal of Medical \& Health Sciences Research. 2011;1(1):37-43.

10. Eweka A.O., Eweka A., Om'iniabohs F.A.E. Histological Studies of the Effects of Monosodium Glutamate of the Fallopian Tubes of Adult Female Wistar Rats. North American Journal of Medical Sciences. 2010;2(3):146-149. doi:10.4297/najms.2010.3146.

11. Hashem H.E., El-Din Safwat M.D., Algaidi S. The effect of monosodium glutamate on the cerebellar cortex of male albino rats and the protective role of vitamin C (histological and immunohistochemical study). J Mol Histol. 2012;43(2):179-186. doi:10.1007/s10735-011-9380-0.

12. Bautista R.J.H., Mahmoud A.M., Königsberg M., Guerrero N.E.L.D. Obesity: Pathophysiology, monosodium glutamate-induced model and anti-obesity medicinal plants. Biomedicine \& Pharmacotherapy. 2019;111:503-516. doi:10.1016/j.biopha.2018.12.108.

13. Amin H.M., Tawfek N.S., Hussein B.K., El-Ghany M.S.A. Anti-Obesity Potential of Orlistat and Amphetamine in Rats Fed on High Fat Diet. Middle East J. Appl. Sci. 2015;4(2):453-461.

14. Amin K.A., Galaly S.R., Hozayen W.G., Ramadan S.M. Effects of Orlistat and Herbal Mixture Extract on Renal Function and 0xidative Stress Biomarkers in a Rat Model of High Fat Diet. International Journal of Biochemistry Research \& Review. 2014;4(2):173-192.
15. Onyema 0.0., Alisi C.S., Ihetuge A.P. Monosodium glutamate induces oxidative stress and affects glucose metabolism in the kidney of rats. Int J Biochem Res Rev. 2012;2:1-11.

16. Foster M., Vanderpool K. Transmission Electron Microscopy Analysis of Visceral and Subcutaneous Lymph Nodes: High Fat Diet-Induced Morphological Changes. The FASEB journal. 2017. https://www.fasebj. org/doi/abs/10.1096/fasebj.31.1_supplement.lb515.

17. Weitman, E.S., Aschen S.Z., Farias-Eisner G. et al. Obesity Impairs Lymphatic Fluid Transport and Dendritic Cell Migration to Lymph Nodes. PLoS One.2013;8(8):700-703. doi:10.1371/journal.pone.0070703.

18. Holovatskyi A.S., Val'ko 0.0., Volkov K.S., Kramar S.B. Submikroskopichni zminy limfoidnykh vuzlykiv klubovykh limfatychnykh vuzliv u dynamitsi khronichnoho opioidnoho vplyvu. [Submicroscopic changes of lymphoid nodules of iliac lymph nodes in the dynamics of chronic opioid influence]. Klinichna anatomiia ta operatyvna khirurhiia. 2018;17(1):35-42. (In Ukrainian).

19. Streich K., Smoczek M., Hegermann J. et al. Dietary lipids accumulate in macrophages and stromal cells and change the microarchitecture of mesenteric lymph nodes. Journal of Advanced Research. 2020;24:291300. doi:10.1016/j.jare.2020.04.020.

\section{ORCID and contributionship:}

Tetiana V. Harapko: 0000-0003-0596-9622 ${ }^{A-D}$

Lesia R. Mateshuk-Vatseba: 0000-0002-3466-5276 ${ }^{\text {E,F }}$

\section{Conflict of interest:}

The Authors declare no conflict of interest.

\section{CORRESPONDING AUTHOR Tetiana V. Harapko \\ Uzhhorod National University \\ 22 Kapushanska st., 88000 Uzhhorod, Ukraine \\ tel: +380506443548 \\ e-mail:garapkotv@gmail.com}

Received: 29.08 .2020

Accepted: 02.06 .2021

A - Work concept and design, B - Data collection and analysis, C - Responsibility for statistical analysis, D-Writing the article, $\mathbf{E}$-Critical review, $\mathbf{F}$ - Final approval of the article 